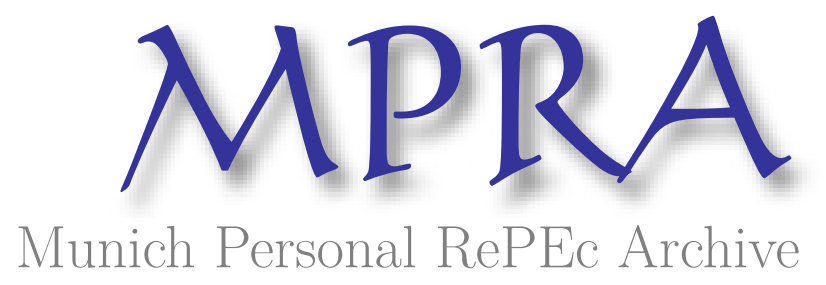

\title{
The Right to Money as the Fundamental Right of Individuals in the Coming Digital Economy
}

Hegadekatti, Kartik

23 April 2017

Online at https://mpra.ub.uni-muenchen.de/82836/

MPRA Paper No. 82836, posted 25 Nov 2017 15:27 UTC 


\section{THE RIGHT TO MONEY AS THE \\ FUNDAMENTAL RIGHT OF INDIVIDUALS \\ IN THE COMING DIGITAL ECONOMY}

\section{Dr.Kartik H \\ Author's email-dr.kartik.h@gmail.com}

\section{ABSTRACT}

Poverty has been a common feature in all human societies since the dawn of civilization. Purchasing power of an individual decides her standard of living. In many cases, it even decides whether a person can live or not (eg: in starvation or malnourishment, victims have no purchasing power to buy calories). As such the Right to Life philosophy of many National Constitutions comes to naught if the state cannot ensure adequate purchasing power to its people. In this paper, we will explore the concept of the Right to Money and how it is linked to the Right to Life.

We will see how the Right to Money concept can ensure a continued economic expansion even in a scenario when automation has reached a critical point (i.e Technological Singularity). Right to Money can also ensure continued human dominance over Machine Intelligence as and when they arise. Interestingly the Right to Money leads to another advanced concept- The Right to Machines which will make certain that there is continued synergy between human and artificial intelligence in future and that the Human race stays relevant. The paper concludes as to how human society can be best prepared economically (or otherwise) for a Post-Technological Singularity scenario. 


\section{INTRODUCTION}

It has been human experience since the dawn of civilization that poverty has been an integral part of almost of all societies. The poor, unable to buy food, become malnourished. This affects their ability to work (if they have any). Less work capability means lesser earnings, further diminishing the power to buy basic necessities and feed the family. Limited earnings and savings constrain a poor person's ability to buy education for his/her children. In such a situation, the next generation is unable to develop capabilities for going up the social strata (in terms of wealth) as a poor person finds it difficult to add value to his/her progeny through education.

We also observe that a person's ability to buy the basic necessities (and some luxuries) of life decides his/her family's well-being. Thus, money that a person possesses, decides whether or not he/she will lead a fair standard of living. Ultimately it all boils down to purchasing power.

It is a known fact that more the disposable income more is the purchasing power and hence, better is the ability to spend. This leads to increased flow of money in the economy, thus raising the amount of disposable income with the people. This is a virtuous cycle. Those laborers (or workers) who earn, spend it in the market. The people who work in the market spend it on various other things and so on.

Lack of money in one's hands decreases her purchasing power. In extreme cases (as seen in many developing nations) this translates to reduced ability to buy food. This turns into starvation in adults and malnourishment in children. It is estimated (according to the United Nations) that 21,000 people die every day of hunger or hunger-related 
causes ${ }^{[1]}$. Thus purchasing power directly translates into living with dignity and respect.

Increasing Automation is causing an increase in unemployment ${ }^{[2]}$. Automation in recent years has reached such an extent that it is leading to 'Jobless Growth' ${ }^{[3]}$, where the economy grows, but jobs are not created.

We can observe that there is "Jobless growth" after every cycle of recession. This "Jobless" is because machines have replaced humans in those jobs and the "growth" is of the companies' top management and investors; not the laborers and workers.

Advances in robotics and artificial intelligence will eventually make a large portion of the human workforce obsolete ${ }^{[4]}$.

Automation will probably continue to displace more and more people leading to humans becoming obsolete in many modern day work places. This leads to a scenario where an ever-increasing population of people are unemployed, pushing them to the brink of poverty, malnutrition and starvation.

Many nations in the world guarantee Right to Life as a fundamental right in their constitutions. As a lack of money (or purchasing power) leads to loss of opportunity to live life with dignity (many times leading to death), it is obvious that Right to Money is a rational extension of the fundamental Right to Life.

By Right to Money, I do not mean to imply that governments should increase welfare subsidies or intensify social security benefits. I propose that due to the changing nature of our economies, and in order to 
maintain the role of humans in Post-Technological Singularity society, we should recognize Right to Money as a fundamental right.

\section{THE RIGHT TO MONEY CONCEPT AND TECHNOLOGICAL SINGULARITY}

Technological Singularity is the hypothesis that the invention of artificial superintelligence will abruptly trigger runaway technological growth, resulting in unfathomable changes to human civilization ${ }^{[5]}$.

It is pertinent to this discussion that we need to keep our economies on an expansionary trajectory in the future. This is necessary to maintain harmony in such a huge population (which by 2050 will reach 9 billion). As machines will be doing most of the labor, it will minimize the need for human labor and in some cases even eliminate the need.

Where will all those laborers go? And machines will not consume items built for human consumption. Humans have to. Thus humans will lose purchasing power (due to unemployment and the need to buy consumables). This will lead to decreased consumption of FMCG products. The industries manufacturing FMCG products make up a substantial chunk of world economy. Many may go bust. People will not buy their products as they will no longer have any disposable income. Other industries will be similarly affected. In the end, a large part of human population will not have enough money to buy goods that machines produce.

Thus we see that machines will be producing stuff that they won't use for people who will have no money to buy it. If by that time Technological Singularity occurs, a truly Artificial Intelligence will have risen. The "Artificial Intelligence" might soon "realize" (or its 
equivalence of "realization") that machines no longer "require" humans as there is no "purpose" to be served by producing items that no one can use. That idle machine power and computing power can then be better used elsewhere, as the AI sees fit. Humans, due to a lack of general or distributed purchasing power will then have become irrelevant in the AI's "scheme of things".

This is not a fictitious scenario or a dystopian possibility. This scenario is plausible and possible as one can infer from the book- The Rise of the Robots by Martin Ford.

The question then is how can human society stay relevant after Technological Singularity and still continue on the trajectory of economic expansion?

It appears that the Right to Money may be the solution to the above question.

The Right to Money can be implemented in the following manner:-

Machines replacing humans will be taxed (a small amount, not prohibitive). Proceeds from the tax will be held in a special fund (The Right to Money Fund). The Right to Money program will have a targeted approach. People who have been displaced by machines will receive a small portion of the fund as a monthly allowance. This will be decided based on various economic parameters. The money should be enough to buy calories for a family of 4 (total) and monthly basic rent. This will be subject to compliance from the person that he/she continues to search for a suitable job. 
The rest of the money in the fund will go as annual allowances to children, as incentives to add value to their capabilities. A person completing high school will get an increment. If she completes a degree or Ph.D she will get another increment and so on. Similarly in other fields like arts, sports etc.

What happens with this process is that people will still have basic purchasing power. Additionally, the next generation will have capabilities (in the form of more Ph.Ds and educated people) to at least understand machine evolution after technological singularity is achieved.

The following events will occur:

(1) Machines will continue to replace humans.

(2) More and more humans will find it difficult to find even petty jobs.

From here, 2 situations can take place (depending on the choice that we, as humans will make)

Situation 1:- Governments do nothing about machines replacing humans and continue with existing policies.

In this situation, we will have a large number of people (mostly youth) who are unemployed. This situation is ripe for civilian unrest. Law and order problems will quickly spiral into social unrest and rebellion.

Situation 2:- Governments implement the Right to Money principle. This will ensure that productivity by machines (replacing humans) translates into some sort of payment to the people who are replaced. Unlike Universal Basic Income, the Right to Money will be a targeted 
program, where over a period of years, governments will invest in its younger generations to develop capabilities and add value to the world economy. The governments must declare Right to Money as a fundamental right in their constitutions.

Human beings will still be relevant as our purchasing power will buy goods produced by the machines, thus providing a "sense of purpose", however elementary. Civil and social unrest due to mass employment can be avoided. Our economies will also continue to grow as machines will carry on manufacturing, services etc. and add value to the economy. Situation 2 also provides a possibility to control future Artificial Intelligence through human purchasing power.

By making "Purchasing Power" as one of the "Purpose Metrics", it might be possible to 'guide' the evolution of Artificial Intelligence to human advantage.

Earlier, due to paper currencies, financial illiteracy and other problems, it was difficult to ensure a principle like Right to Money.

In the coming age of digital money (cryptocurrencies and Blockchains) it is possible to ensure that every citizen is covered under the Right to Money.

As discussed elsewhere, machines will be able to "mine" cryptocurrencies [6]. Interestingly, as Blockchain technology puts discretion into the ambit of machines, it (Blockchain technology) will be an important instrument in the evolution of a future AI. Rather than humans, machines will "earn". We need to ensure that they will "earn" for us. As we have seen that improved automation will take purchasing power away from the hands of the people, Right to Money ensures that governments restore basic purchasing power back to the people. As 
machines will be the earning members of the society in future, Right to Money translates to Right to Machines i.e every human being who is born will own a machine, a 'smart device' that will 'mine' crytptocurrencies for them. This will be the logical next step.

Again, Blockchain technology makes it possible to provide machines with unique identities. Machines can have a virtual presence on the Blockchain which can be owned by humans. Thus, we may be looking at a scenario, where as a part of Right to Machines, every child will be allotted a "smart device", immediately on her birth by the government (or society). This smart device will "mine" cryptocurrency for the child. As she grows up, a steady income through the smart device is ensured, thus automatically ensuring "Right to Money". In such an eventuality, the government has to only ensure that a smart device is allotted (as entitled) to a new born child. Once the whole population is covered under the Right to Machines, there is automatic implementation of the Right to Money.

\section{$\underline{\text { Right to Money Vis - a - Vis Universal Basic Income (UBI) }}$}

(1) As already discussed, Unlike Universal Basic Income, Right to Money is not linked to Right to freedom but Right to Life ${ }^{[7]}$.

(2) Universal Basic Income proposes blanket coverage of all citizens. The downside is that, it may reduce the drive to work. There is also a danger that the money may lead to addiction of alcohol and drugs. Right to Money on the other hand, is targeted. Those who have no income or savings are assured of a basic income (though not universal) subject to some conditions. These restraints should exist because just as governments confer Right to Money, citizens are 
obliged to certain duties. The "duties" clause ensures that the citizen continues to search for work.

(3) Universal Basic Income is not incentive linked and does not seek to add value or capabilities to coming generations. Right to Money on the other hand is incentivized value addition to the next generation. This is achieved through Right to Machines.

(4) Universal Basic Income entails an increase in taxation ${ }^{[8]}$. Consequently there is reduction in the Taxation revenues as the money needed to fund Universal Basic Income will be a large number. Right to Money on the other hand ensures steady economic expansion since it is targeted and incentivized value addition. As the population of humans increases, more people owning 'smart devices' will come under the ambit of Right to Money. Machines will go on manufacturing products for the increasing population of human beings, thus increasing GDP leading to continued economic growth.

(5) Universal Basic Income does not addresses problem of Technological Singularity or provide solution to mass unemployment situation arising out of increased automation. Right to Money can be realized by implementing Right to Machines, thus addressing the problem of Technological Singularity and the ascendancy of AI.

(6) A commission of the German parliament discussed basic income in 2013 and concluded that it would cause a rise in the shadow economy ${ }^{[9]}$. But in case of Right to Money, Blockchains and crypto networks will ensure that money is not diverted to the shadow economy ${ }^{[10]}$. 
(7) The commission of the German parliament which discussed basic income in 2013 also concluded that the corresponding rise of taxes would cause more inequality: higher taxes would translate into higher prices of everyday products, harming the finances of poor people. Inflation would also be increased due to the blanket coverage. But Right to Money is targeted and part of the larger Programmable Economy, thus less inflationary and more equal.

(8) Here, Right to Money is being proposed as a better mode of income distribution and not as a concept opposed to Universal Basic Income. Presently, Universal Basic Income is needed to ensure income equality and lift masses out of poverty. But by the time the modalities for Universal Basic Income are worked out and implemented, Technological Singularity might already have occurred. We may therefore very well direct our efforts now itself to work out an income distribution Scheme in a Post-Technological Singularity situation.

(9) In its elementary form Right to Money actually envisages a type of Basic Income (though not universal). By implementing Right to Machines, we are ensuring Right to Money. At the same time, we are also linking machines to 'earn' for humans, thus providing them with a 'purpose'. Therefore, by the time Technological Singularity is attained, many Machines will be linked to human life 'earning' for the humans to who machines ('smart devices') are allotted. In this manner, humans will be relevant to the AI as it will have a 'purpose' of existence. 


\section{CONCLUSION}

Machines will reach Technological Singularity when the first fully functional AI will be created, and Blockchain technology will have a major role to play. We have seen that the Right to Money is more basic in nature as it is linked to Right to Life. It provides us a solution where purchasing power that we might lose (due to machines replacing humans at the workplace) will be restored back to us in a planned way. Right to Money, provides a way out, where in case of an independent AI developing in future, we may still be able to control it to our advantage and stay relevant. At the same time we can continue on the path of economic growth.

We also observed that Right to machines is a logical extension of Right to Money as "smart devices" can become earners, putting purchase power directly into the hands of people. In such cases, the governments can discontinue (any existing) basic incomes without violating the fundamental right of "Right to money". Governments will be fulfilling Right to Money by ensuring Right to Machines.

Right to Machines will in turn allow us to control machines (and AI) through ownership (enabled by Blockchain and other financial technologies),thereby providing a 'Sense of Purpose' to the burgeoning machine numbers.

We thus see that as more developments occur in areas of technology, especially financial technologies, we need to be aware of the opportunities and possibilities that will open up and be prepared for them. 


\section{REFERENCES}

[1] http://www.poverty.com/

[2] http://www.acting-man.com/?p=32134 Retrieved 04 april 2017

[3] "Forum Debate: Rethinking Technology and Employment <-Centrality of work, 1:02 - 1:04 -->". World Economic Forum. Jan 2014. Retrieved 14 July 2015.

[4] "Martin Ford Asks: Will Automation Lead to Economic Collapse?" SingularityHub. December 15, 2009. Retrieved June 22, 2015

[5] Singularity hypotheses: A Scientific and Philosophical Assessment. Dordrecht: Springer. 2012. pp. 1-2. ISBN 9783642325601

[6] Hegadekatti, Kartik, Automation Processes and Blockchain Systems (December 27, 2016). Available at SSRN: https://ssrn.com/abstract=2890435

[7] Moseley, Daniel, A Lockean Argument for Basic Income (June 25, 2011). Basic Income Studies, Vol. 6, No. 2, 2011. Available at SSRN: https://ssrn.com/abstract $=1872580$

[8]https://fee.org/articles/a-universal-basic-income-would-meanmassive-tax-hikes/

[9] "Deutscher Bundestag - Problematische Auswirkungen auf Arbeitsanreize" (in German). Bundestag.de. Retrieved 5 June 2016

[10] Hegadekatti, Kartik, Regulating the Deep Web Through Controlled Blockchains and Crypto-Currency Networks (December 22, 2016). Available at SSRN: https://ssrn.com/abstract $=2888744$ 